\title{
DIREITOS INTELECTUAIS E CONHECIMENTOS TRADICIONAIS: ESTUDO DO CASO GUARANI-MBYÁ FACE AO INSTITUTO DO PATRIMÔNIO HISTÓRICO E ARTÍSTICO NACIONAL - IPHAN
}

\author{
João Mitia Antunha Barbosa* \\ Marco Antonio Barbosa**
}

\begin{abstract}
Resumo: Os sistemas tradicionais de proteção da propriedade intelectual apresentam certas limitações quando se trata de proteger o patrimônio e os conhecimentos tradicionais, tornando-se fundamental a reflexão jurídica sobre um sistema de proteção sui generis mesmo que não venha a resolver todas as questões envolvidas, devendo-se, no entanto, reconhecer avanços já obtidos por meio de Declarações e Convenções internacionais, dispositivos legais nacionais, como no Brasil, objeto principal deste estudo, podendo-se concluir tratar-se de um debate, legislação e processo de negociação, apenas iniciais, que, mesmo assim, oferecem reais perspectivas de utilização seja dos clássicos instrumentos de proteção dos direitos intelectuais quanto de sistema sui generis, devendo levar-se em consideração as particularidades de cada situação para o acesso a tais conhecimentos, atendendo a exigências éticas, sempre com a participação e envolvimento dos detentores desses conhecimentos e dos poderes públicos, como o caso analisado dos Guarani-Mbyá demonstra.
\end{abstract}

Palavras-chave: conhecimentos tradicionais; direitos intelectuais; guarani-mbyá; povo.

Summary: Traditional systems of intellectual property protection have certain limitations when it comes to protecting the heritage and traditional knowledge, becoming fundamental legal reflection on a sui generis system of protection even that will not solve all the issues involved, which should, however, recognize progress already achieved through international declarations and conventions, national legal provisions, as in Brazil, the main object of this study can be concluded that this is a debate, legislation and negotiation process, only initials, which nevertheless offer real prospects of use is the classic instruments of protection of intellectual property rights as a sui generis system, and that they take into account the particularities of each situation for access to such knowledge, given the demands ethical, always with the participation and involvement of the holders of such knowledge and the public authorities, as the case analyzed the Guarani Mbyá shows.

Keywords: intellectual property rights; guarani-mbyá; people; traditional knowledge.

\section{Introdução}

A relação entre direitos intelectuais e conhecimentos tradicionais até esta data situa-se em patamar ainda bastante inicial, seja do ponto de vista legal, quanto jurisprudencial e doutrinário. A legislação brasileira relativa à proteção desses conhecimentos é recente, as decisões judiciais são poucas e mesmo a doutrina sobre o assunto é escassa. Os documentos internacionais, por sua vez, são bastante genéricos e

\footnotetext{
* Advogado. Doutor em Direito, pela Universidade de São Paulo e Universidade de Angers, França, professor de Direito e indigenista da Fundação Nacional do Índio - FUNAI.

Advogado. Doutor em Direito, pela Universidade de São Paulo e professor e pesquisador do Programa de Mestrado em Direito da Sociedade da Informação da FMU - SP.
} 
não permitem a configuração de um modelo regulatório completo. Assim, não existe um modelo regulatório hegemônico em prática em razão, sobretudo, dos conflitos políticos abertos e acirrados entre os envolvidos com a questão: governos, organismos internacionais, organizações não governamentais, povos autóctones, comunidades tradicionais, políticos, interessados na exploração econômica desses conhecimentos, cientistas, doutrinadores, entre outros atores.

Existem posições das mais variadas quanto à exploração e/ou aproveitamento dos conhecimentos e das diferentes expressões do patrimônio cultural tradicional indígena e das comunidades tradicionais. Elas vão desde a rejeição completa de qualquer tipo de aproveitamento com fins econômicos ou de mercado, passando pelas posições intermediárias, que postulam uma conciliação entre os interesses envolvidos com a exploração econômica e a preservação desse mesmo patrimônio cultural, até se chegar ao extremo oposto, na perspectiva mais clássica do mercado e seus interesses mais imediatos (BARBOSA, 2012, p 443).

Adiante, serão focadas as formas de tratamento dos conhecimentos tradicionais sobre a diversidade biológica e o estado da arte, em seguida, as definições de populações e de conhecimentos tradicionais e as dificuldades que encerram. Na continuação, aborda-se o debate internacional relativo ao conhecimento tradicional, seguido pela análise do alcance e dos limites dos diversos instrumentos legais que podem ser usados para a proteção dos conhecimentos tradicionais, por fim, se discute o caso Guarani-Mbyá, que diz respeito ao projeto do Instituto do Patrimônio Histórico e Artístico Nacional - IPHAN - relativo ao inventário que pretende proceder sobre os conhecimentos imateriais desse povo, as questões suscitadas e o posicionamento adotado pelos líderes e representantes deste mesmo povo. A conclusão é dedicada à abordagem dos mais evidentes problemas que o tema encerra com apreciação mais detalhada do caso específico Guarani-Mbyá.

\section{Formas de tratamento dos conhecimentos tradicionais sobre a biodiversidade: 0 estado da arte}

Entre as diferentes formas de tratamento jurídico com as quais o patrimônio cultural dos povos indígenas e das comunidades tradicionais em seu conjunto está 
confrontado vêm se destacando, tanto do ponto de vista legislativo, como jurisprudencial e doutrinário, as que dizem respeito aos conhecimentos tradicionais sobre a diversidade biológica e sua relação com o sistema de proteção da propriedade intelectual (BARBOSA, 2012, p.409). É exatamente neste campo que tem sido produzido o maior número de instrumentos legais internacionais e nacionais, pedidos de autorização para pesquisas, exploração e disputas, inclusive no plano judicial (idem).

No Brasil, relativamente a esse campo -diversidade biológica -, a Constituição Federal de 1988 prevê no art. 225, II, a proteção de biodiversidade, que também determina a preservação dos diferentes ecossistemas, considerando-os como patrimônio nacional. O mesmo artigo prevê ainda a proteção da diversidade genética (§ $1^{\circ}$, II e V), regulamentada pela Lei no 11.105 , de 2005 - Lei de Biossegurança.

Na sequência, em 1992, realizou-se no Rio de Janeiro a Conferência das Nações Unidas para o Meio Ambiente, quando foi adotada a Convenção da Diversidade Biológica (CDB) à qual o Brasil aderiu (aprovada pelo Congresso Nacional em 1994) (BARBOSA, 2012, p. 406-407). Trata-se de uma convenção-quadro que possibilita às legislações dos países aderentes sua regulação posterior, embora tenha definido certos princípios normativos, entre eles o de considerar os recursos biológicos e genéticos nos limites das soberanias estatais e não mais como patrimônio comum da humanidade e sob a premissa geral da busca em compatibilizar proteção dos recursos biológicos com desenvolvimento social e econômico. Ela reconhece, logo no preâmbulo, que muitas comunidades dependem dos recursos biológicos para sobreviver, destacando a importância de serem preservados os conhecimentos relativos a tais recursos e a necessária repartição dos benefícios econômicos no caso de sua aplicação comercial. Seu objetivo geral é a utilização sustentável e a conservação da diversidade biológica, com repartição justa e equitativa dos benefícios decorrentes da sua aplicação. Para tanto, prevê no art. 15, como principal instrumento de proteção dos conhecimentos tradicionais, o consentimento prévio fundamentado e o compartilhamento de benefícios com as comunidades tradicionais, de acordo com a previsão do art. 8 (j) (BARBOSA, 2012, p.408-409).

A partir de então, conferências vêm sendo realizadas entre as partes signatárias da convenção (CDB) visando atingir os seus objetivos, sendo que a $10^{\mathrm{a}} \mathrm{e}$ 
última (CoP -10) ocorreu em Nagoya no Japão, no ano de 2010, quando foi assinado protocolo relativo ao acesso aos recursos genéticos advindos da biodiversidade, sua exploração comercial e a repartição dos benefícios decorrentes. Nessa ocasião, estabeleceu-se que cada país é soberano sobre os recursos genéticos de sua biodiversidade e que o acesso a eles deve ter o seu consentimento e os lucros que decorrerem da exploração devem ser repartidos entre o país explorador e o país detentor dos recursos. Além disso, o art. 5.1 bis insiste sobre a necessidade de que cada país adote as medidas necessárias para que ocorra o consentimento prévio e informado das comunidades locais nessas transações, em todas as etapas. Tanto do processo de negociação do uso da biodiversidade quanto do conhecimento tradicional associado. Sugere ainda que as partes desenvolvam modelo de cláusulas contratuais sobre a repartição de benefícios com as comunidades, porém, conferindo espaço para outras modalidades de regulação. Por sua vez, o relatório do encontro "ad hoc" de discussões sobre o art. 8 (j) da CDB sugere que sejam levados em consideração em um sistema "sui generis" de proteção ao conhecimento tradicional as práticas locais e as normas costumeiras, na perspectiva do pluralismo jurídico, que considera o direito estatal apenas como uma dentre tantas outras formas de direito.

Nessa mesma ocasião, ainda em Nagoya, ficou consignado que as Partes devem tomar medidas para monitorar a utilização dos recursos genéticos e garantir maior acesso à informação sobre os conhecimentos a eles associados e o artigo 16 trata da necessidade de elaboração de códigos de conduta relativos aos conhecimentos tradicionais associados à biodiversidade. Uma segunda frente de preocupações, objeto do $10^{\circ}$ encontro das Partes, referiu-se ao estabelecimento de metas para a redução da perda da biodiversidade, uma vez que a maioria dos países não cumpriu as metas estipuladas para 2010. Finalmente, a terceira frente de preocupações diz respeito à inclusão da biodiversidade nas contas públicas dos países e a necessidade de diminuição de subsídios destinados a atividades predatórias da biodiversidade.

Especificamente no Brasil, o poder executivo regulamentou a um só tempo, tanto a Convenção da Diversidade Biológica (CDB) em seus artigos $1^{\circ}, 8$ (j), 10(c), 15 e 16 (3 e 4) quanto o inciso II do $\S 1^{\circ}$ e o $\S 4^{\circ}$, do art. 225 da Constituição Federal, por meio da Medida Provisória n 2052 de 2000, reeditada em 2001, sob n ${ }^{\circ}$ 2186-16.Apesar da existência de projetos de lei sobre o tema e dos protestos e argumentos contrários 
advindos de diferentes setores sociais, é a MP 2186-16 que ainda se encontra em vigor(BARBOSA, 2012, p.413-415, AZEVEDO \& AZEVEDO, 2001). Trata-se do marco inicial da regulamentação da proteção aos conhecimentos tradicionais no Brasil e dispõe sobre a repartição dos benefícios oriundos da exploração do patrimônio genético e do conhecimento tradicional associado, bem como ao acesso à tecnologia e à transferência de tecnologia para a conservação e a utilização desse patrimônio e desses conhecimentos. Conclui-se que o que a Medida Provisória disciplina é, na verdade, a apropriação de patrimônio pertencente a todos ou conhecimentos coletivos das comunidades tradicionais, visto que o artigo $4^{\circ}$ submete o acesso à autorização do poder público federal. Para as comunidades tradicionais que criam, desenvolvem ou detêm o conhecimento associado o artigo $9^{\circ}$ prevê os direitos de ver indicada a origem do conhecimento em todas as publicações, utilizações, explorações e divulgações; de impedir terceiros não autorizados de realizar qualquer tipo de pesquisas ou explorações relacionadas aos conhecimentos; de impedir todo tipo de divulgação desses conhecimentos por parte de terceiros não autorizados; de receber benefícios pela exploração econômica por terceiros, direta ou indiretamente, do conhecimento tradicional associado, cujos direitos são de sua titularidade (BARBOSA, idem).

Para a obtenção desses benefícios deve haver negociação específica, cujas modalidades constam de rol taxativo do artigo 25 e que incluem: divisão de lucros; pagamento de royalties; acesso e transferência de tecnologias; licenciamento, livre de ônus, de produtos e processos e capacitação de recursos humanos (BARBOSA, 2012, p. 420-421). A mais geral observação feita por especialistas sobre a matéria é que resta em aberto saber se de fato haveria vantagens para os detentores dos conhecimentos tradicionais nessa legislação pela previsão de tais benefícios ou se, na verdade, os reais beneficiados não seriam aqueles com o acesso concedido (BARBOSA, 2012, p. 409).

Para a regulamentação da Medida Provisória três Decretos foram baixados: o Decreto $\mathrm{n}^{\mathrm{o}}$ 3.945, de 2001, que define a composição do Conselho de Gestão do Patrimônio Genético (CGEN), conselho responsável pelas autorizações de utilização do patrimônio genético, e as normas de seu funcionamento; o Decreto $\mathrm{n}^{\circ} 5.459$, de 2005 , que regulamenta o artigo 30 da MP, disciplinando as sanções ao desrespeito das normas de acesso ao patrimônio genético e ao conhecimento tradicional associado e o Decreto $n^{\circ} 6.915$ de 2009, que define a distribuição das parcelas dos lucros e dos royalties 
resultantes da exploração econômica de processo ou produto desenvolvido a partir de amostras de componente do patrimônio genético. O Instituto Nacional de Propriedade Intelectual - INPI, órgão responsável pela concessão de patentes e o CGEN, por sua vez, editaram resoluções para regulamentar o procedimento.

Por outro lado, deve ser lembrado que o sistema de patentes no Brasil decorre do "Trade-Related Aspects of Intellectual Property Rights" - TRIPS-, que foi incorporado no ordenamento jurídico e regulamentado pela Lei de Propriedade Industrial $n^{\circ}$ 9279, de 1996, cuja tônica principal é a competição industrial e não a preservação dos conhecimentos tradicionais e a diversidade biológica. Aliás, o TRIPS não se refere aos conhecimentos tradicionais, cuja competência é deixada aos países signatários, prevendo apenas que aqueles países que não quiserem permitir patenteamento de plantas devem adotar sistema "sui generis" para a sua proteção.

Como se sabe, por meio do TRIPS, os Estados Unidos vincularam sanções comerciais à exigência de uma proteção mínima à propriedade intelectual pelos países membros da Convenção de Cultivares. Assim, o que se nota no seio da Organização Mundial do Comércio -OMC- são reivindicações para alteração no sistema de propriedade intelectual, com novas exigências para o patenteamento e, em conjunto com a Organização Mundial da Propriedade Intelectual - OMPI-, sustenta argumentos no sentido de que a proteção dos conhecimentos tradicionais pode encontrar espaço dentro do próprio sistema de patentes tradicional, enquanto que no seio da $\mathrm{CDB}$ e das Conferências das Partes os maiores argumentos têm sido no sentido da criação de um regime "sui generis" de proteção. O mesmo se verifica no âmbito da Organização das Nações Unidas -ONU- na Declaração sobre Biopirataria e Direitos Comunitários de Johannesburgo, que também não acolhe a ideia de proteção dos conhecimentos tradicionais pelo sistema de patentes (HURTADO, 1999, p.28).

Por sua vez, a Lei n 9.279, de 1996 - Lei de Propriedade Industrial, não trata da proteção do conhecimento tradicional associado e não admite patente sobre plantas e a lei relativa aos direitos autorais, de $\mathrm{n}^{\mathbf{0}}$ 9.610, de 1998, de modo geral, considera a originalidade da obra como requisito para a configuração dos direitos assegurados, embora o artigo 45 que dispõe sobre as obras pertencentes ao domínio público tenha excetuado dessa condição os conhecimentos étnicos e tradicionais. 
No que se refere à proteção vegetal, a Lei $\mathrm{n}^{\circ}$ 9.610, de 1980, Lei de Cultivares, protege as variedades de vegetais e apenas permite o registro desde que sejam cumpridos os requisitos da estabilidade, homogeneidade e distintividade, sem, no entanto, contemplar os conhecimentos tradicionais.

Assim, constata-se que no Brasil não existe um sistema de proteção dos conhecimentos tradicionais advindo do poder legislativo, a despeito de muitas proposições em andamento, de modo que o tema tem sido disciplinado e tratado por ação do poder executivo, como se demonstrou acima. A despeito disso, organizações internacionais das quais o país faz parte pressionam para que se crie um sistema protetivo, seja no âmbito tradicional de patente, seja então, criando regimes jurídicos específicos.

\section{População tradicional e conhecimentos tradicionais: definições e dificuldades}

Outra questão fundamental sobre o tema é a definição de população tradicional, em que se situam os povos indígenas e que não goza de consenso, seja na legislação, seja entre os autores que tratam do tema. A definição legal que vem servindo de base para a legislação posterior é a contida no artigo 20, da Lei 9.985, de 2000, que dispõe sobre o Sistema Nacional de Unidades de Conservação - SNUC. O núcleo do conceito situa-se na exigência de baixo impacto ambiental da ação antrópica e no seu papel fundamental para a proteção ambiental.

Esse conceito legal considera a relação de abrigo das populações com uma área natural; sua dependência da exploração dos recursos naturais dessa área; a sustentabilidade dessa exploração; que esse sistema de exploração desenvolva-se ao longo de gerações; forma adaptada às condições ecológicas locais e, finalmente, o desempenho de proteção da natureza e a manutenção da biodiversidade, por meio dessas atividades. Tratam-se esses de critérios que vêm sendo utilizados na maior parte dos diplomas ambientais posteriores, ressaltando como principais as condições de baixo impacto ambiental e/ou contribuição para a proteção da biodiversidade e, portanto, determinantes para a compreensão do que se entende por população tradicional. Conclui-se que o art. 8 (j) da $\mathrm{CDB}$ é redigido no mesmo sentido ao afirmar a 
necessidade de respeitar, preservar e manter o conhecimento, inovações e práticas das comunidades locais e populações tradicionais, com estilos de vida tradicionais relevantes à conservação e à utilização sustentável da diversidade biológica. No mesmo artigo, define também o que entende por conhecimentos tradicionais, como: “conhecimentos, inovações e práticas de comunidades locais e populações indígenas com estilos de vida tradicionais relevantes à conservação e à utilização sustentável da diversidade biológica”.

Quanto ao conceito de conhecimento tradicional, tudo indica que a doutrina, as organizações e as instituições ligadas ao tema, concordam sobre pelo menos os seguintes pontos: que o conhecimento tradicional guarda diferença em relação ao conhecimento da sociedade circundante, no que se refere aos ideais e pressupostos de seu conhecimento específico, que tem como centralidade o local onde é utilizado, integrando também o conhecimento externo que foi se introduzindo na comunidade ao longo do tempo; tratar-se de uma informação sistemática, mas que, no entanto, é mantida oralmente; tratar-se do conjunto de todos os saberes e de práticas, implícitas e/ou explícitas e que são aplicadas na vida socioeconômica e ecológica; tratar-se do conjunto das experiências e do conhecimento de um grupo étnico e que se constitui na base para a tomada de decisões relativas a conflitos familiares, criado de forma interna e com elementos externos, porém, internamente integrados, em razão de capacidade do próprio grupo em absorver conhecimentos relevantes; enfim, tratar-se de conhecimento localizado, tradicional e único, que foi desenvolvido em razão de condições específicas de dada comunidade situada em determinada área geográfica (BARBOSA, 2012, p. 449).

\section{0 debate internacional relativo aos conhecimentos tradicionais}

O surgimento do debate sobre conhecimento tradicional na cena internacional pode ser localizado primeiro nas discussões sobre o direito de autor durante a Conferência de Estocolmo, em 1967, que levantou a preocupação com as obras não publicadas e com aquelas em que o autor não pode ser individualmente identificado, ocasião em que a tradição popular passa a ser objeto de atenção, sob a denominação de folclore, cujas características de oralidade e de pertencimento a um grupo ou comunidade foram percebidas como fragilidades, em razão do que deveria ser 
protegido. Um segundo momento pode ser localizado nos debates internacionais sobre os direitos internacionais indígenas e sobre a natureza, destacando-se o papel dos povos indígenas e dos movimentos sociais e ambientalistas que passaram a ter presença constante e cada vez maior nas reuniões da ONU, desde a década de 1980, ampliando os debates sobre os conhecimentos dos povos indígenas e comunidades tradicionais relacionados à proteção da biodiversidade (BARBOSA, 2012, p.211).

É necessário destacar, neste contexto, que o papel de protagonismo desempenhado especialmente pelos representantes de povos indígenas foi além dos aspectos específicos sobre a importância dos conhecimentos tradicionais sobre a natureza, tendo suas contribuições ampliado o debate em diversos planos, tais como o espiritual, o filosófico, o ético e as amplas consequências para a vida e o planeta.

Na sequência, o debate se amplia atingindo a conjunção de preocupações relacionadas com o patrimônio cultural e natural, remetendo as atenções não mais apenas aos mecanismos de proteção dos produtos da cultura como também aos seus portadores, sem o que se concluiu que não seria possível proteger o patrimônio (CUELLAR, 2004, p.19).

Isso impôs a difícil questão decorrente da condição coletiva desses titulares. $\mathrm{Na}$ mesma ordem de preocupação, foi acrescentada a de se saber como conciliar a proteção da capacidade criativa com a exploração econômica. Assim, no âmbito da Organização das Nações Unidas para a Educação, a Ciência e a Cultura - UNESCO-, já em 1999, a Conferência Internacional de Washington reconheceu que o "patrimônio cultural abarca não apenas os produtos artísticos, mas também os conhecimentos e valores que tornaram possível sua criação" (CUELLAR, 2004, p.19, BARBOSA, 2012, p. 239-242). Com isso, os modos de interação, através dos quais os processos criativos se tornam possíveis e adquirem valor, também passam a ser visados como objetos de proteção.

Será, no entanto, com a Declaração Universal da Diversidade Cultural, de 2001, que a UNESCO institui nova ética, ao proclamar a necessidade de proteção da diversidade cultural. Considera a diversidade cultural tão necessária para o gênero humano quanto a diversidade biológica para a natureza. Enfatiza a necessidade de que 
sejam respeitados e protegidos os sistemas de conhecimento tradicional, especialmente os dos povos autóctones (indígenas), bem como de que seja reconhecida a contribuição dos conhecimentos tradicionais para a proteção ambiental e a gestão dos recursos naturais, incitando a que sejam favorecidas as sinergias entre a ciência moderna e os conhecimentos locais (BARBOSA, 2012, p. 376).

Patrimônio cultural e proteção dos conhecimentos tradicionais passam então a ser claramente vinculados e, preservar os conhecimentos transmitidos de geração em geração dos povos tradicionais toma o significado da garantia da diversidade cultural. Tanto em sua condição de patrimônio tangível quanto intangível, além da preservação da natureza, ao se reconhecer que esses grupos humanos dispõem de conhecimentos e práticas não predatórias do meio natural (LE SCOUARNEC, 2004, p. 26-30).

\section{Alcance e limites dos diversos instrumentos legais que podem ser usados para a proteção dos conhecimentos tradicionais}

Em complemento e já na perspectiva de instrumentos legais vinculativos, foi adotada em 2003, ainda pela UNESCO, a Convenção para a Salvaguarda do Patrimônio Cultural Imaterial, definindo no seu artigo $2^{\circ}$ o patrimônio cultural imaterial como "as práticas, representações, expressões, conhecimentos e técnicas - junto com os instrumentos, objetos, artefatos e lugares culturais que lhes são associados - que as comunidades, os grupos e, em alguns casos os indivíduos reconhecem como parte integrante de seu patrimônio cultural". Esse patrimônio cultural imaterial, que se transmite de geração em geração, é constantemente recriado pelas comunidades e grupos em função de seu ambiente, de sua interação com a natureza e de sua história, gerando um sentimento de identidade e continuidade, contribuindo assim para promover o respeito à diversidade cultural e à criatividade humana (CUELLAR, 2004, p. 19-20; BARBOSA, 2012, p. 381-382).

Assim, usos e saberes passam a ser tratados como formas de expressão do patrimônio cultural e da própria identidade de um povo, constituindo-se, ao mesmo tempo, na base para a proteção aos ambientes naturais a eles vinculados. Isso levou muitos especialistas a sustentarem que o debate é afastado das questões relativas ao estatuto da propriedade intelectual desses saberes, e com isso superando alguns dos 
impasses entre a CDB e a OMPI. Desse modo, já em outro patamar de discussão, os conhecimentos tradicionais, a exemplo do que ocorre no âmbito da CDB, ganham centralidade e as discussões internacionais atuais se dão por meio da combinação das diversas frentes que envolvem o patrimônio cultural, a biodiversidade, a exploração sustentável e os conhecimentos tradicionais, que não devem ser pensados de forma estanque.

Por sua vez, o sistema de patente, forma de proteção mais difundida, não tem se mostrado adequado para a proteção dos conhecimentos tradicionais ao mesmo tempo em que se choca com outras disposições internacionais, que enfatizam a necessidade de adoção de um sistema "sui generis" para a proteção dos conhecimentos tradicionais.

Tendo em vista o objetivo deste ensaio de analisar alguns dos principais instrumentos disponíveis nos diferentes sistemas de proteção de direitos e que podem, ao menos em tese, servir ao propósito de proteção dos conhecimentos tradicionais, cabe referir que existem ainda outros instrumentos concernentes à propriedade intelectual, como é o caso da marca registrada. Ela já é utilizada, sobretudo, para a proteção de produtos tradicionais artísticos e culturais o que permite a prorrogação da proteção por tempo indefinido, com a previsão também de propriedade coletiva, o que possibilita atender a muitos aspectos específicos dos conhecimentos tradicionais. No entanto, por meio dela é possível evitar o uso das marcas já protegidas, mas não do conhecimento tradicional em si, nem dos modos de fazer (savoir-faire), tampouco das tecnologias que o incorporam, sendo que por esse meio o conhecimento tradicional acaba recebendo status de mercadoria a ser vendida e não de conhecimento enquanto tal, sendo certo que nem todas as comunidades tradicionais ou povos indígenas desejam ver seus conhecimentos explorados ou negociados no mercado. Acrescenta-se como dificuldade para a utilização da marca o fato de que ela só pode ser atribuída quando é possível identificar claramente o seu detentor e o território específico. Porém, muitas vezes, o conhecimento tradicional é compartilhado entre diferentes comunidades e também em diferentes territórios, o que dificulta a sua adequada utilização nesses casos (BARBOSA, 2012, p. 201-202). 
Outro instrumento disponível dentro do sistema de patente é a indicação geográfica, por meio de nome que indica a origem geográfica específica de um produto e que guarda estreita semelhança com a marca registrada. A TRIPS prevê as indicações geográficas determinando que os países membros da OMC adotem medidas para coibir o uso de uma indicação geográfica para evitar confusão ou que leve a um "fair competition". As desvantagens neste caso são semelhantes às apresentadas quanto às marcas registradas. No caso, fica a proteção do próprio conhecimento tradicional em si em segundo plano e pode ganhar proteção apenas o conhecimento específico que a comunidade queira comercializar. Devem-se considerar ainda os custos implicados dos registros que ficam a cargo de particulares. Ademais, deve-se registrar que a proliferação de indicações geográficas tenderia a reduzir o valor individual do produto. Por outro lado, o uso da indicação geográfica como termo genérico é outro problema suplementar, que pode ser livremente utilizado. Acrescenta-se como outra limitação para a sua utilização no âmbito dos conhecimentos tradicionais o fato de que só é permitida a proteção por indicação geográfica quando a qualidade de um produto está ligada à sua produção em determinada região, em termos humanos e naturais. Isso acarreta dificuldade para sua aprovação e também ela não pode ser licenciada. A necessidade de se ter que provar a ligação entre produto e localidade faz com que a cultura seja necessariamente ligada ao território. É necessário fazer "prova de origem" e registro histórico de uso contínuo das práticas para obter a proteção e a proibição de licenciamento implica em que as comunidades tradicionais não possam exercer seus direitos em outros locais diferentes daquele de sua origem (BARBOSA, 2012, p. 202203).

Outro instrumento disponível e possível de ser utilizado para a proteção dos conhecimentos tradicionais denomina-se "divulgação de origem geográfica de recursos genéticos em requerimento de patentes" e diz respeito à necessidade de informação sobre a origem dos recursos genéticos em questão e da autorização prévia da comunidade e país onde foram obtidos. Aponta-se como benefícios a transparência e a harmonização do TRIPS com a CDB. Trata-se de um mecanismo que transfere o ônus da prova do provedor para o utilizador do recurso, constituindo-se em mecanismo do mercado para controlar o uso pelo próprio mercado, tendo, alguns países, já incorporado em suas legislações essas diretrizes, entre eles o Brasil. A desvantagem em relação aos conhecimentos tradicionais é a de não solucionar os casos de crimes em que as patentes 
não estão envolvidas. Além disso, mesmo entre as patentes, grande parte dos recursos, envolvendo conhecimentos tradicionais, pode ser obtida sem que o pesquisador ou requerente tenha que ir à fonte desses conhecimentos. Com isso, a medida acaba por ser aplicável a número bastante reduzido de patentes. Acrescenta-se como dificuldade suplementar o fato de que algumas vezes são vários os conhecimentos relacionados a uma só patente, tornando difícil a definição daqueles que são ou não essenciais. A OMPI fez a sugestão de criação de "um sistema através do qual os órgãos encarregados do exame de pedidos de patente que identificam a fonte geográfica dos recursos genéticos ou do conhecimento tradicional possam transmitir a informação, seja ao país interessado ou à OMPI, que poderia agir como depositária de informações sobre patentes em casos de alegada biopirataria". Todavia, o caso de sementes para alimentação e agricultura não estão sujeitos ao regime de patentes, mas ao da União Internacional para a Proteção de Obtenções Vegetais - UPOV-(idem).

A proteção de informação confidencial é outro mecanismo à disposição, previsto no art. 39 do acordo TRIPS. Ele apresenta desvantagem para aplicação ao conhecimento tradicional uma vez que neste caso específico a informação não será confidencial no seio da comunidade tradicional concernida. Nesse caso não se pode falar propriamente de confidencialidade. Ademais, há que ser considerado o fator de incerteza envolvido em relação ao costume das comunidades no que se refere aos seus padrões de confidencialidade. Por fim, de qualquer forma, o valor cultural ou espiritual de determinado conhecimento pode não ser protegido na aplicação comercial do conhecimento, ainda que feita em confidencialidade (BARBOSA, 2012, p. 194-201).

A aplicação de leis de concorrência desleal, em um regime internacional, outro mecanismo de proteção a ser lembrado, apresenta já de partida o problema relativo à compreensão do seu significado, que é determinado dentro de cada país. Igualmente, coloca-se a questão de se saber qual será o padrão adotado para identificar o que irá ser considerado como conduta desleal ou desonesta, cabendo sempre ao aplicador nacional das sanções e remédios locais o dever de considerar esses padrões no nível internacional e na localidade de onde vem o pedido de proteção.

Relativamente aos cultivares e aos direitos dos agricultores há dois principais sistemas: o TRIPS e as convenções da UPOV, sendo que em 1961 a UPOV 
implementou a Convenção Internacional de Proteção de Novas Variedades de Plantas. Ela foi revisada em 1972, 1978 e 1991. As duas últimas, atualmente em vigor, preveem tanto o sistema de patentes quanto o "sui generis" para a proteção de variedades de plantas. O sistema "sui generis" de proteção, desenvolvido especificamente para as necessidades dos agricultores, não conflita com a adoção do TRIPS que dá aos Estados flexibilidade de proteger as novas variedades de plantas, seja com um sistema de patentes, seja com um sistema "sui generis", ou ainda com a combinação de ambos. Muitos países se tornaram signatários da Convenção apenas recentemente, especialmente os em desenvolvimento e os em transição para a economia de mercado. $\mathrm{O}$ Brasil aderiu em 1999. Esta versão de 1999 aumenta o número de espécies protegidas de cinco para quinze e estabelece: (i) que, em dez anos, todas as variedades de plantas devem estar protegidas no âmbito do Tratado; (ii) um conceito para variedade; (iii) permite a proteção tanto por direitos dos agricultores quanto por meio de patente; (iv) amplia consideravelmente as situações em que a autorização do agricultor é necessária, incluindo importação, exportação, condicionamento e estocagem, e também as plantas já colhidas, desde que a colheita tenha sido não autorizada, e permite que os Estados criem outros direitos não previstos no ato; (v) aumenta a proteção mínima de quinze para vinte anos, e de dezoito para vinte e cinco anos no caso de videiras, árvores de floresta ou de frutas e plantas ornamentais; (vi) reduz as exceções e limitações aos direitos exclusivos para o caso de atividades privadas e não comerciais, fora do controle dos agricultores (como agricultura de subsistência), e para pesquisa científica não direcionada à exploração comercial. A isenção do receptor é fortemente restringida: perde-se a liberdade de criação de novas variedades "essencialmente derivadas" das já protegidas. Ou seja, o benefício do livre acesso é revogado. Mantem-se o privilégio do agricultor, mas, desta vez, resguardando os interesses do receptor, isto é, pagando-se royalties pela utilização da variedade, ainda que as sementes utilizadas provenham de colheita anterior. Esse ato de 1991 recebeu muita crítica de vários países em desenvolvimento. A União Africana, em 1999, manifestou-se pelo congelamento da proteção de plantas por meio da propriedade intelectual, até que um sistema adequado de reconhecimento das práticas de cultivo de comunidades indígenas fosse desenvolvido e até 2009, na África, apenas a Tunísia e o Marrocos haviam adotado o ato de 1991, enquanto que o Quênia e a África do Sul adotaram o de 1978. Países sulamericanos signatários do ato de 1978 têm sido pressionados para adotar o de 1991 (BARBOSA, 2012, p.339-344). 
A diminuição constatada da importância dos Tratados UPOV coincide com o surgimento do TRIPS, embora este último dê pouca importância aos direitos dos agricultores. Ele permite que os países signatários protejam as variedades de plantas, por meio de patentes ou por sistema "sui generis" de proteção. Exige que os países adotem formas de "enforcement" dos direitos de propriedade intelectual, podendo o detentor de um direito sobre uma variedade de planta mover ação judicial contra quem vender aquela variedade sem autorização, podendo, assim, obter reparação por danos. $\mathrm{O}$ Conselho do Tratado solicitou em 1998, 2001 e 2002 aos países membros da OMC declaração a mais clara possível a respeito de como protegiam suas variedades de plantas, além de ter organizado informações sobre as práticas nacionais de cultivares. É importante referir que o TRIPS dispõe de um sistema próprio de solução de disputas, com isso podendo tornar mais efetivas suas previsões. Teoricamente, o fato da existência desse órgão, sugere a ideia de maior obediência voluntária às previsões convencionais não havendo, no entanto, até o momento, registros de ações movidas no seu âmbito, em relação aos cultivares. Como os países em desenvolvimento passaram a ser obrigados a proteger suas variedades de plantas apenas a partir de 2000, ocasião em que efetivamente ingressam no TRIPS, quando muitos deles ainda não tinham um sistema nacional de proteção, supõe-se que o sistema de solução de disputas, antes mencionado, venha em breve a ser acionado para exigir que determinados países cumpram suas obrigações assumidas no Tratado, solução que pode ser vista com ceticismo devido tanto aos avanços esperados da Rodada de Doha, à incapacidade de agricultores em mobilizarem seus países para o cumprimento do tratado e às poucas previsões do TRIPS relativas aos cultivares. Diferentemente do que ocorre em relação aos direitos autorais e patentes, para os quais o TRIPS exige a adesão às Convenções de Berna e de Paris, respectivamente, no caso específico da UPOV não há qualquer referência no mesmo sentido, ficando os membros da OMC desobrigados em relação aos atos da UPOV e a discricionariedade permitida aos países para adotarem o sistema de patentes ou um sistema "sui generis", ou a combinação de ambos, não é harmônica, dando ao mesmo tempo liberdade aos países o que não existe em outras áreas (idem).

Por um lado, se a obtenção de patentes é mais complicada do que a adoção de sistema "sui generis", em razão das complexas exigências de exigibilidade, acrescido do requisito de novidade, do passo inventivo e da aplicação industrial, por outro, ela 
confere amplos direitos ao detentor contra terceiros, sendo que os sistemas "sui generis" para proteção de direitos dos agricultores têm padrões mais baixos de exigibilidade, mas dão aos detentores apenas alguns direitos em relação à utilização por terceiros.

A adoção de ouvidoria ou de defensoria pública é outra possibilidade identificada de proteção dos conhecimentos tradicionais, com a função de investigar os abusos contra comunidades tradicionais. Essa é uma solução puramente administrativa. A desvantagem que se identifica é a de submeter esses interesses à disposição dos governos nacionais, que em muitos países não têm a determinação política de realmente defendê-los, acrescida da complexidade operacional e financeira (BARBOSA, 2012, p. 456).

A repartição de benefício é mais uma modalidade para a proteção dos conhecimentos tradicionais, que se baseia na autorização de acesso, em geral por parte dos governos dos países onde existem esses conhecimentos, sob a forma de regimes contratuais voluntários, que dizem respeito ao acesso ao conhecimento e à repartição dos benefícios. Essa solução é a prevista na CDB, conforme já antes analisado e adotada pela MP 2.186/2001 no Brasil. Como desvantagem há que se observar que o poder de barganha mostra-se desigual entre as partes contratantes, além do fato de que as comunidades indígenas e tradicionais têm pouca ou nenhuma experiência para lidar com esse tipo de contrato. Em países onde é prevista, como o Brasil, as ONGs, ligadas a atividades de capacitação e de prestação de serviços jurídicos, acabam por desempenhar papel central, o que pode em muitos casos significar excessivo poder concedido a essas mesmas ONGs (BARBOSA, 2012, p.456).

Além das soluções antes mencionadas, é necessário também lembrar o modelo baseado em códigos de conduta não vinculantes, cuja aplicação verifica-se tanto no âmbito internacional, em documentos oficiais de organizações, como em diferentes países. A vantagem desses códigos é a de serem objetos de ampla negociação, recebendo contribuiçõoes das partes envolvidas e de não resultarem de negociações de cúpula. A desvantagem mais evidente é a de não terem sua aplicação garantida legalmente, podendo simplesmente ser ignorados pelos que negociarem diretamente com as comunidades tradicionais (idem). 
Os registros públicos e as bases de dados constituem-se em alternativas de proteção dos conhecimentos tradicionais, igualmente em prática. Tratam-se, também, de medidas meramente administrativas, em franca expansão em muitos países, sobretudo com o auxilio da Internet, catalogando-se o conhecimento tradicional existente. $\mathrm{O}$ CGEN tem essa como uma de suas competências, conforme o que dispõe o art. 11 da MP 2186-16. Outros países adotam sistemas semelhantes. A vantagem é que tais bases de dados permitem constituir um sistema de classificação estruturado dos conhecimentos, baseado na classificação internacional de patentes, fazendo com que o acesso à informação evite a concessão de patentes injustificadas e permite maior monitoramento por parte da administração pública. Uma importante questão é a relativa ao consentimento prévio e informado por parte dos detentores dos conhecimentos tradicionais permitindo que os conhecimentos integrem tais registros públicos ou bancos de dados. Outra é, porém, a questão que se coloca em relação ao fato de que muitos dos conhecimentos tradicionais não são escritos. Acrescenta-se como complicador o fato de que muitos examinadores de patentes, em determinados países, não fazem pesquisa relativa à novidade de invenção em outros países, como é o caso dos Estados Unidos. Questão não menos importante implicada nesse tipo de solução refere-se à própria publicação dos conhecimentos tradicionais o que permite afirmar que uma vez estando em domínio público não mais pertenceriam ao detentor original de forma exclusiva. Além disso, estando publicados nesses registros ou bases de dados, é possível supor que possam vir a ser utilizados para o desenvolvimento de novos produtos. Igualmente, é questionada a possibilidade de se limitar o acesso às bases de dados prevendo-se um tipo de compensação aos detentores dos conhecimentos (BARBOSA, 2012, p.413-423).

Essa questão foi tratada diretamente pelo primeiro dos autores deste artigo quando da realização de Oficinas de capacitação desenvolvidas junto ao povo GuaraniMbyá do Brasil, no ano de 2010, por iniciativa do IPHAN em conjunto com a Organização Não Governamental: Centro de Trabalho Indigenista -CTI -, exatamente em razão da pretensão do IPHAN de desenvolver o Inventário Nacional de Referências Culturais, dentro do qual existe o objetivo de compilar a cultura imaterial guarani-mbyá, como será discutido a seguir. 


\section{Os Guarani-Mbyá e o Instituto do Patrimônio Histórico e Artístico Nacional - IPHAN}

Durante as oficinas promovidas pelo IPHAN em parceria com o CTI, no ano de 2010, verificou-se a resistência dos líderes Guarani-Mbyá em autorizar o registro de certas práticas, sobretudo as religiosas, em grande parte por várias das razões já discutidas neste ensaio enquanto dificuldades identificadas nos diversos mecanismos de proteção existentes em sua aplicação para a proteção dos conhecimentos tradicionais. Outro aspecto que foi levantado pelas lideranças guarani reunidas referia-se à questão do consentimento, que segundo eles deveria ser obtido caso a caso, junto às diferentes comunidades guarani, na perspectiva da autonomia política de cada uma delas. O trabalho de registro pretendido pelo IPHAN deveria, segundo eles, levar em consideração as demandas locais e específicas das comunidades, quanto ao que considerassem que deveria ser objeto desses registros. As discussões ocorridas nesses encontros permitem uma reflexão e uma contribuição jurídica sobre Direitos Culturais e Intelectuais Indígenas, sobretudo pela insistência particularmente sobre as questões legais que se referem diretamente - mesmo que apenas de modo tangível - ao universo da cultura imaterial (e material) do povo idígena Guarani-Mbyá no Brasil. Estas reflexões proveem essencialmente de três oficinais jurídicas organizadas pelas instituições já referidas, conjuntamente com os chefes e outras autoridades guarani, no quadro de estudos e de debates que precederam, em uma etapa preliminar, a aplicação do Inventário Nacional de Referencias Culturais - INRC - do Instituto do Patrimônio Histórico e Artístico Nacional - IPHAN. Tanto nas oficinas quanto nas intervenções dos participantes, foi possível identificar os principais temas que orientaram a dinâmica dos trabalhos realizados que são reveladores da tonalidade das preocupações expressadas por ocasião desses encontros, como se verá adiante na conclusão.

\section{Conclusão}

O sistema internacional da propriedade intelectual faz prova a uma só vez de um caráter universalizante e discriminatório vis a vis das expressões e registros culturais dos povos indígenas e comunidades tradicionais. Ele pode assegurar a proteção das produções intelectuais, mas segundo critérios exclusivamente ocidentais. Fora desse esquema, as criações, obtenções e expressões culturais ficam pura e simplesmente ao 
alcance da biopirataria, da apropriação por terceiros não componentes da própria comunidade, ou ainda de caírem no domínio público ou no folclore. O caráter discriminatório desse sistema fica evidente quando constrange as populações tradicionais a se ajustarem aos modelos externos, sob o risco real de interferir em suas práticas, seus costumes e seus valores. No entanto, começam a ser esboçadas iniciativas para resolver esse problema. Desde o fim dos anos 70 e início dos anos 80, organismos internacionais, como a UNESCO e a OMPI, vêm trabalhando em colaboração com as populações locais e os povos indígenas, com a finalidade de refletir e de redigir um projeto coerente de regime "sui generis" dos direitos intelectuais, visando proteger de modo eficaz as diversas expressões culturais.

Os dirigentes Guarani-Mbyá têm afirmado que esse tipo de reflexão e de iniciativa deve ser amplamente buscado e desenvolvido por todas as instituições que os apoiam, sobretudo pelo Instituto do Patrimônio Histórico Nacional - IPHAN-. A existência de politicas específicas por parte das organizações governamentais e não governamentais, não as dispensam de participarem da pesquisa visando à adoção de uma legislação de propriedade intelectual mais justa e adaptada às demandas dos povos indígenas e das comunidades tradicionais em seu conjunto. Essa se trata de uma reivindicação constante dos dirigentes Guarani-Mbyá que participam do projeto desenvolvido pelo IPHAN com a colaboração do CTI.

A capacidade de reunir e de mobilizar forças em seu favor tem sido uma das marcas do movimento indígena nacional. A Constituição de 1988 é um exemplo, que traduziu e exprimiu o reconhecimento e a obtenção de direitos até então inéditos para os povos indígenas do Brasil. O artigo 231 afirma que: "são reconhecidos os direitos originários sobre a terra, a organização social, os costumes, as línguas, crenças e tradições" das populações indígenas. E paralelamente o artigo 215 , dispõe que: "O Estado garantirá a todos o pleno exercício dos direitos culturais e o acesso às fontes da cultura nacional, apoiará e encorajará a valorização e a difusão das manifestações culturais. $\S 1^{\circ}$ - O Estado protegerá as manifestações das culturas populares, indígenas e afro-brasileiras, e de todos os outros grupos participantes do processo da civilização nacional". Finalmente, adotando tendência internacional, estabelece no seu artigo 216 que, constituindo um patrimônio cultural brasileiro, os bens de natureza material e imaterial, tomados individual ou conjuntamente, portadores de referência à identidade, à 
ação, à memória dos diferentes grupos que formam a sociedade brasileira, entre as quais: I - as formas de expressão; II- Os modos de criar, de fazer e de viver; III- As criações científicas, artísticas e tecnológicas; IV- As obras, objetos, documentos, construções e outros espaços destinados às manifestações artísticas e culturais; V - Os conjuntos urbanos e os sítios de valor histórico, paisagístico, artístico, arqueológico, paleontológico, ecológico e científico. - $\$ 1^{\circ}$ - O Poder Público, em colaboração com a comunidade, desenvolverá e protegerá o patrimônio cultural brasileiro, por meio de inventários, de registros, de fiscalização, de proteção e de desapropriação, e de outras formas de precaução e de preservação.

Essa legislação inovadora inaugurou nova tendência, oferecendo uma perspectiva auspiciosa para a garantia e a salvaguarda dos direitos intelectuais indígenas e das populações tradicionais em geral. No entanto, certas ponderações são aguardadas e mostram-se necessárias para responder a outras questões levantadas pelos dirigentes indígenas, o que evitaria fricções e desacordos por ocasião da fase de realização do inventario propriamente dito.

Segundo o compromisso assumido pelo $\S 1^{\circ}$ do artigo 216, da Constituição Federal de 1988, o Estado brasileiro inaugurou, no ano 2000, seu Programa Nacional do Patrimônio Imaterial - PNPI -, criando, pelo decreto 3551/00, o Registro dos Bens Culturais de Natureza Imaterial, o Inventário Nacional de Referências Culturais INRC, e os Planos de Preservação. Trata-se de um programa inovador que dá continuidade, como já afirmado, à orientação da Constituição de 1988, cujo objetivo é de "contribuir para a preservação da diversidade étnica e cultural do país, e à disseminação de informações sobre o patrimônio cultural brasileiro a todos os segmentos da sociedade". Essas grandes linhas de orientação reforçam igualmente a intenção de favorecer a inclusão social dos detentores do patrimônio cultural, alargar sua participação, estipular a salvaguarda dos bens culturais e, acima de tudo, assegurarlhes as condições materiais de vida digna, respeitando e protegendo seus direitos difusos ou coletivos em relação com esse patrimônio.

As grandes linhas dessa politica do PNPI são: promover a inclusão social e a melhoria das condições de vida dos produtores e dos detentores do patrimônio cultural imaterial; aumentar a participação dos grupos que produzem, transmitem e atualizam as 
manifestações culturais de natureza imaterial nos projetos de preservação e de valorização desse patrimônio; promover a salvaguarda dos bens culturais imateriais, melhorando as condições materiais que favoreçam sua existência, assim como pelo alargamento do acesso aos benefícios que eles geram; adotar mecanismos para proteger os bens culturais imateriais em situação de risco; respeitar e proteger os direitos difusos ou coletivos relativos à preservação e ao uso do patrimônio cultural imaterial.

Esse conjunto de premissas de trabalho do IPHAN foi bem acolhido pelos dirigentes Guarani-Mbyá. Ele demonstra, de fato, que o projeto do Estado brasileiro e do Instituto do Patrimônio Histórico e Artístico Nacional concernente ao patrimônio imaterial ultrapassa largamente o estrito inventário. Esse Inventário Nacional de Referências Culturais é um instrumento importante de proteção, assim como o Registro dos Bens Culturais de Natureza Imaterial e os Planos de Salvaguarda. No entanto, dúvidas a seu respeito foram apresentadas por ocasião das oficinas de reflexão, que merecem ser esclarecidas.

Segundo o artigo $1^{\circ}$ do Decreto 3551/00: é criado o Registro de Bens Culturais de Natureza Imaterial que constituem o patrimônio cultural brasileiro. Segundo o $\S 1^{\mathbf{0}}$ - O registro será feito em um dos seguintes livros: I- Livro de Registro dos Conhecimentos, no qual serão inscritos os conhecimentos e "savoir-faire" pertencentes ao cotidiano das comunidades; II- Livro de Registro das Celebrações, no qual serão inscritos os rituais e as festas que pontuam a vida coletiva do trabalho, da religiosidade, dos divertimentos e outras práticas da vida social; III- Livro de Registro das Formas de Expressão, no qual serão inscritas as manifestações literárias, musicais, plásticas, cênicas e lúdicas; IV- Livro de Registro dos Lugares, no qual serão inscritos os mercados, feiras, santuários, praças e outros espaços onde se concentram e se perpetuam as práticas culturais coletivas. Segundo o $\S 2^{\circ}$, a inscrição em um desses livros terá sempre como referência a continuidade histórica do bem e a sua significação nacional para a memória, a identidade e a formação da sociedade brasileira.

De acordo com a ideia do artigo 216 da CF transposta para o artigo $1^{\circ}$ do Decreto 3551/00, o "patrimônio cultural imaterial" Guarani-Mbyá pode (e deve) ser reconhecido e salvaguardado enquanto patrimônio cultural da "Nação brasileira", e particularmente se isso representar uma maior garantia de preservação e valorização dos 
saberes, conhecimentos, expressões, tradições e cultura Guarani. Porém, os responsáveis e os dirigentes Guarani-Mbyá expressaram claramente por ocasião das referidas oficinas, que esse patrimônio sagrado e essas referências culturais que poderão ser objeto do inventário, são em primeiro lugar o Patrimônio do Povo Guarani-Mbyá. Expressaram igualmente o desejo da comunidade de registrar formalmente essa observação nos documentos oficiais. Afirmaram que contam para tanto com o apoio e a colaboração do IPHAN e do CTI. Essa posição por parte dos representantes indígenas é absolutamente coerente com as orientações da política do PNPI e com as recentes convenções internacionais ratificadas pelo Brasil, sobretudo com a Convenção 169 da Organização Internacional do Trabalho - OIT - sobre Povos Indígenas e Tribais -, bem como com o parágrafo único do artigo $9^{\circ}$ da MP 2186-16, que afirma que: “(...) todo conhecimento tradicional associado ao patrimônio genético poderá ser propriedade da comunidade (...)".

Tal atitude firme por parte dos representantes Guarani revela sua obrigação ética em relação a um povo que ultrapassa as fronteiras do território brasileiro. O povo Guarani, assim como suas expressões culturais comuns, ocupa desde tempos imemoriais um território que se estende, para além do território do Brasil, ao do Paraguai, Uruguai, Argentina e Bolívia. É nesse sentido que eles insistem sobre a titularidade Guarani de seu patrimônio cultural. O fato de o Brasil elevar essas expressões à categoria de patrimônio cultural da "Nação" significa o reconhecimento de que esse povo, que existe antes do próprio Estado, contribuiu histórica, política e culturalmente na formação do Brasil de hoje. Esse reconhecimento e essa valorização cultural não deveria de forma alguma entrar em confronto com a vontade do povo Guarani de preservar a titularidade coletiva de seu patrimônio, apesar de certas perspectivas alarmistas que ponderam no sentido de que os dirigentes Guarani, em aceitando a corresponsabilidade do projeto, estariam renunciando deliberadamente ao seu patrimônio ancestral em favor da "Nação Brasileira", deixando-o derrapar para a esfera do folclore e do domínio público.

Esse tipo de interpretação deve ser refutado - e cabe ao IPHAN tomar posição para demonstrar a sua inexatidão - para que se realizem de modo livremente consentido os objetivos superiores de valorização e defesa do patrimônio e das expressões culturais imateriais Guarani-Mbyá. Os dirigentes Guarani afirmaram ainda 
que aguardam essa definição do IPHAN para poder em seguida apresentar formalmente o projeto a sua comunidade e aos anciãos, verdadeiros titulares desse patrimônio.

O projeto deve ser visto como uma iniciativa nobre, portadora de imenso potencial que significa o reconhecimento positivo e de garantias para uma forma de cultura e de vida diferente e resistente, que soube permanecer viva e recriar suas tradições, malgrado a falta de apoio legal durante tanto tempo. Constata-se assim uma mudança progressiva, como essa iniciativa do IPHAN comprova, ao se reconhecer que o Patrimônio Cultural Imaterial Guarani faz também parte da história cultural da Nação Brasileira. Evidentemente, isso significa também que a mudança de orientação não terá futuro a não ser que as pessoas que atuam no campo dito "cultural" se engajem para apoiar as demandas dos povos indígenas e exerçam influência sobre o campo do direito da propriedade intelectual "sui generis" propriamente dito.

Finalmente, é necessário destacar outro aspecto da política de desenvolvimento do PNPI que gerou dúvidas por ocasião das oficinas. A Resolução $n^{\circ}$ 001 (do IPHAN), de 03 de agosto de 2006, dispõe no artigo 10 que: "conforme ao Decreto $n^{\circ} 3551 / 2000$, a fim de assegurar ao bem proposto ao Registro uma ampla divulgação e promoção, a instituição responsável pela instrução técnica do processo administrativo do Registro deverá: ceder gratuitamente ao IPHAN os direitos de autor que serão destinados à promoção, divulgação e comercialização sem fim lucrativo; e o direito de utilização e de reprodução em diversas formas, dos produtos e derivados resultantes do trabalho de instrução técnica, sempre preservando o crédito ao autor (...)".

A propósito, os dirigentes e os outros responsáveis indígenas presentes nas já mencionadas oficinas afirmaram que eles não têm a autonomia necessária para ceder a título pessoal esses direitos de autor, sendo imprescindível passar por um acordo amplo envolvendo toda a comunidade, reconhecida como autora coletiva e, portanto titular dos direitos morais e patrimoniais decorrentes. Segundo eles ainda, o artigo 10 da Resolução 001, do IPHAN, antes citado, deve ser discutido com a comunidade. Na opinião dos autores deste ensaio ele deve até mesmo eventualmente ser reconsiderado pelo próprio IPHAN, neste caso específico, posto que a cessão de direitos ao IPHAN acompanhada da divulgação e comercialização das informações não se constitui em unanimidade no seio do Povo Guarani-Mbyá, mesmo em se tratando de fins não 
lucrativos. Para tanto, seria necessário aplicar as exigências do "Consentimento Prévio, Livre e Informado", imposto pela Convenção 169 da OIT, respeitando igualmente a "vontade", a "dimensão do segredo" e o "tempo" Guarani. De fato, o mencionado artigo 10 da Resolução $n^{\circ}$ 001/2006 (no caso específico deste projeto) oferece o risco de conflitar com a luta para fazer reconhecer os direitos de autor do povo Guarani, com as determinações da Convenção 169 da OIT (quanto ao consentimento prévio, livre e informado), e eventualmente com as próprias linhas diretivas do PNPI.

\section{Referências}

AZEVEDO, C.M. do A. \& AZEVEDO, E.de A. A trajetória inacabada de uma regulamentação. Disponível em http://www.comciencia.br/reportagens/biodiversidade/bio11.htm, acesso em 06/02/2013.

BARBOSA, J. M. A. Les lieux des savoirs autochtones : Identité, territoire et droits intellectuels. Berlin, Éditions Universitaires Européennes, 2012.

CUELLAR, J. P. de. "La variable culturelle”. In: Le Patrioine Culturel Immatériel, les enjeux, les problématiques, les pratiques. Internationale de L'imaginaire.

Nouvelle Série - $\mathrm{n}^{\mathbf{0}}$ 17, Babel, Maison des cultures du monde, Arles: Actes sud, 2004, p. 19-25.

HURTADO, L.M. "El conocimento tradicional. Conférencia à Madrid em novembro 1997’. In: ZURITA, A.O. de. Ibis (org.). Ni robo ni limosina: Los Pueblos Indigenas y la Propriedad Intelectual. Santa Cruz: CEJIS, CABI, CIDOB, 1998.

LE SCOUANEC, F.P. "Quelques enjeux liés au patrimoine culturel immatériel». In: Le Patrioine Culturel Immatériel, les enjeux, les problématiques, les pratiques.

Internationale de L'imaginaire. Nouvelle Série $-\mathrm{n}^{\circ} 17$, Babel, Maison des cultures du monde, Arles : Actes sud, 2004, p. 26-40. 